\title{
Comments: totally endoscopic (VATS) first rib resection for thoracic outlet syndrome
}

\author{
Bo Povlsen \\ Department of Orthopaedic Surgery, Guy's \& St Thomas' Hospital, London, UK \\ Correspondence to: Bo Povlsen. 19 Arragon Gardens, West Wickham, Kent BR4 9LJ, London, UK. Email: bo@manusmedical.com. \\ Provenance: This is an invited Commentary commissioned by the Section Editor Feichao Bao (Department of Thoracic Surgery, The First Affiliated \\ Hospital, Zhejiang University, Hangzhou, China). \\ Comment on: George RS, Milton R, Chaudhuri N, et al. Totally Endoscopic (VATS) First Rib Resection for Thoracic Outlet Syndrome. Ann Thorac \\ Surg 2017;103:241-245.
}

Submitted Oct 24, 2016. Accepted for publication Oct 30, 2016.

doi: $10.21037 /$ jtd.2016.12.09

View this article at: http://dx.doi.org/10.21037/jtd.2016.12.09

\section{Dear Editor,}

It is an honour to be asked to write a comment on the paper by George et al. (1) as I have a particular interest in the treatment of Thoracic Outlet Syndrome as I have been the main author on the most recent Cochrane review on Treatment for thoracic outlet syndrome (2).

I congratulate the team from St. James, Leeds on their reported successful treatment with this "new" treatment. However, I feel it appropriate to express a few words of caution regarding the bold statements that are expressed in the paper and at the same time raise some concerns regarding the evidence base for which new treatment should be introduced in order to comply with the legal requirement for consent to treatment (3), which are particular relevant in the UK after the Montgomery ruling in 2015 (4).

* The abstract state that "Surgical resection is curative"-but later the in the same paper there is a statement that "Potential complications associated with rib resection for TOS include chylothorax, paresthesia, neurovascular injury, and persistent pneumothorax. Poor long-term functional results are dictated by the presence of acute ischemia, poor systemized neurological symptoms as presenting symptoms, and severe postoperative complications" (5);

* I disagree with the first statement but agree with the $2^{\text {nd }}$ statement. I am of the opinion that there is ample literature to support that surgical success is not always guaranteed;

* The authors further stated that "the safety of this method was assured based on a case series by Ghefter and co-workers (6). However that case series only contained two patients and I wonder if this new method had obtained ethical approval before it was used in Leeds and whether the patients enrolled in this series were aware that in the hands of the Leeds surgeons this was "experimental" surgery and represented uncharted territory?

* There is no mention of a learning curve for this technique in the hands of the Leeds surgeon(s) and there is no information about how many patients were operated before the current series was started. I am of the opinion that such information is highly relevant to any other centres who want to adopt this "superior" method, particularly as the outcomes are so encouraging;

* The frequency of the performed procedures was one case every 10 months by the Leeds team but there is no mention about how many of the five authors operated the patients, i.e., case/surgeon/year;

* My last question to George et al. is: are they planning to conduct a randomised controlled trial comparing non-surgical to Totally Endoscopic First Rib Resection for Thoracic Outlet Syndrome? There is still a fundamental yet unanswered question as to what the best treatment for Thoracic Outlet Syndrome is. To my knowledge no study has yet shown that surgery is better than non-operative treatment, though the paper by Sheth and Campbell (7) has suggested that 
if patients are operated then the transaxillary first rib resection resulted in superior results compared to Supraclavicular neuroplasty of the brachial. However, to answer the question whether Totally Endoscopic First Rib Resection is better or worse than other surgical procedures require a proper powered prospective randomised control trial—and I would encourage George et al. to initiate that, for the benefit of future TOS patients.

\section{Acknowledgements}

None.

\section{Footnote}

Conflicts of Interest: The author has no conflicts of interest to declare.

\section{References}

1. George RS, Milton R, Chaudhuri N, et al. Totally

Cite this article as: Povlsen B. Comments: totally endoscopic (VATS) first rib resection for thoracic outlet syndrome. J Thorac Dis 2016;8(12):E1739-E1740. doi: 10.21037/ jtd.2016.12.09
Endoscopic (VATS) First Rib Resection for Thoracic Outlet Syndrome. Ann Thorac Surg 2017;103:241-245.

2. Povlsen B, Hansson T, Povlsen SD. Treatment for thoracic outlet syndrome. Cochrane Database Syst Rev 2014;(11):CD007218.

3. GMC Guidelines. Consent: patients and doctors making decisions together. Available online: http://www.gmc-uk. org/guidance/ethical_guidance/consent_guidance_index.asp

4. JUDGMENT Montgomery (Appellant) $v$ Lanarkshire Health Board (Respondent) (Scotland). Available online: https://www.supremecourt.uk/decided-cases/docs/ UKSC_2013_0136_Judgment.pdf

5. Degeorges R, Reynaud C, Becquemin JP. Thoracic outlet syndrome surgery: long-term functional results. Ann Vasc Surg 2004;18:558-65.

6. Ghefter MC, Yoshida WB, Cataneo DC, et al. Thoracic outlet syndrome - cervical rib resection by video-assisted thoracoscopic surgery. J Vasc Bras 2012;11:219-25.

7. Sheth RN, Campbell JN. Surgical treatment of thoracic outlet syndrome: a randomized trial comparing two operations. J Neurosurg Spine 2005;3:355-63. 